\title{
The brain-life theory: towards a consistent biological definition of humanness
}

\author{
John M Goldenring Department of Pediatrics, New York Medical College, Valhalla, New York, 10595
}

\section{Author's abstract}

This paper suggests that medically the term a'human being' should be defined by the presence of an active human brain. The brain is the only unique and irreplaceable organ in the human body, as the orchestrator of all organ systems and the seat of personality. Thus, the presence or absence of brain life truly defines the presence or absence of human life in the medical sense. When viewed in this way, human life may be seen as a continuous spectrum between the onset of brain life in utero (eight weeks gestation), until the occurrence of brain death. At any point human tissue or organ systems may be present, but without the presence of a functional human brain, these do not constitute a 'human being', at least in a medical sense. The implications of this theory for various ethical concerns such as in vitro fertilisation and abortion are discussed. This theory is the most consistent possible for the definition of a human being with no contradictions inherent.

However, having a good theory of definition of a 'human being' does not necessarily solve the ethical problems discussed herein.

Over the last four years in the United States another round of controversy about therapeutic abortions has begun. Just as in earlier debates, an apparent key issue has been the question of when human life begins. Scientists and physicians who appeared before a US Senate Committee either stated that human life began at conception or that it began some time later, probably at the point where the fetus could survive outside the womb (the 'viability' theory), but that they were not quite sure (1).

In the autumn of 1984 the matter was specifically raised during domestic issue debates between US Presidential candidates. President Reagan noted his belief that a fetus warranted constitutional protection as soon as it became a human being. He said that he must believe this occurred at the moment of conception unless scientists could more clearly establish when human life began.

Over the past year, several abortion clinics have been bombed by zealots claiming that they are avenging the 'murder' of fetuses. The divisiveness of the issue is

\section{Key words}

Abortion; brain life theory; humanness. clearly increasing.

Despite the worsening situation and the President's unexpected challenge, scientists seem to feel impotent and unable to aid the public in developing a consensus which could contribute to a societally acceptable solution to the abortion question.

Yet scientists and physicians have no difficulty in stating when a human being is alive so long as it has been born. I would contend that the process of birth, while still significant, is not any longer so important that it should render us tongue-tied as if witnessing an inexplicable miracle. There must be some point before birth when a human being truly begins to be alive. Can our medical scientific knowledge be used to define this point?

For over a decade, I have advocated a third position between an at-conception theory of biological humanness and the viability theory $(2,3)$. Called the 'brain-life theory' this view suggests that the fetus is biologically a human being at the point at which its brain begins to function. In this decade, in 1981, the theory was propounded in a letter in the New England Fournal of Medicine (4). More recently, that letter was discussed in the fournal of Medical Ethics (5).

The purpose of this paper is to give the brain-life theory and its implications a fuller treatment than could be achieved in the short length of a letter. Hopefully this airing, coupled with the previous articles, will result in the closer consideration by ethicists, scientists and physicians and politicians which it richly deserves.

The potential implications of this alternative theory are also extremely important for diverse other issues besides abortion such as birth control, treatment of rape victims, fetal research, in vitro fertilisation (6), and even the disposal of fetal remains. Even more difficult issues, for example cloning and brain transplantation, may loom ahead in the next century and may also be affected by our view of when human life begins.

The major points on which the discussion which follows hinge are three:

1) Physicians have always had a working definition of human life because they have for centuries been called upon to declare death. The definition of death, may, as 
I contend, imply its converse - a working definition of what constitutes life.

2) With regard to this 'medical definition of human life', there is no reason from the point of view of physiology why fetal humans should be viewed as different from born humans.

3) While a consistent theory of human beginning has potential implications for making ethical decisions, knowing of it does not necessarily solve ethical dilemmas. But it can go a long way towards making ethical choices clearer, and may serve to point the way to a broadly acceptable societal ethical consensus. And it can minimise the amount of uncomfortable paradoxes which can occur using other definitions of biological humanness.

Before proceeding to the discussion, I need to state a few semantic definitions for the sake of clarity. I will be using the nouns 'human', 'human being' and 'fullhuman' synonymously to refer to creatures with the appropriate chromosomal material. The adjective 'human' may also be applied to tissues with the appropriate chromosomal material, but which I will argue are not sufficiently organised in a biological sense to be considered 'human beings'. The word 'humanness' also will refer to that which in the above sense qualifies biologically and genetically as 'human'. No non-biological implications should be attached to these words, though I will discuss the possible valueladen choices available once the basic biological definitions are established.

Therefore, I will seldom use the word 'person' in this paper, because I will be attempting to make scientifically based definitions which are relatively 'value-free' and objective. The term 'person' is highly value-laden and has many meanings depending on the society in which one lives. A 'person' is a human being accorded full rights, protection and respect. Inherent in the definition of 'person' may be many developmental, religious and social criteria.

I will contend that the definition of 'human being' has implications for the definition of a 'person', but that those terms may not be synonymous.

\section{The brain-life theory of humanness}

Regardless of culture, physicians or those who take their role in society have been required to know when human life has ended. After all, no aid can be brought to the dead, only comfort to the bereaved. A physician who treated cadavers would have been in a sorry state indeed.

Physicians, therefore, very early recognised that there were certain 'vital functions' necessarily required to maintain life. When these ceased, a person was dead. The practitioner therefore chose to measure various 'vital signs' as indicators of the presence or absence of these necessary functions. This practical approach is still in clinical use and all that has changed over the centuries has been the sophistication of measurement, and assessment of which vital signs are of paramount importance.

From time immemorial, the most important 'vital $\overrightarrow{\bar{Z}}$. signs' were heartbeat and respiration, and clinicallye? these are still the primary indicators of the state of $a=$ patient. However, in the past two decades science has developed an ability both to replace respiratory and? cardiac function mechanically or to transplant the $\frac{\bar{\sigma}}{\bar{c}}$ heart and lungs, thus restoring lost functions. A 'vital sign' which could be restored virtually at will posed a serious set of problems with which all ethicists arew familiar.

Fortunately, it had long been clear that the brain, $\stackrel{\circ}{\longrightarrow}$ the seat of consciousness, emotion and an individual's $\vec{\omega}$ unique personality held the most central vital function? in the body. Without its co-ordinating action, the organs of a body would be like discordant instruments in a conductorless orchestra - functional perhaps, but. unable to play together anything recognisable as $a \overrightarrow{\overrightarrow{0}}$ musical composition.

Consider, if you will, the case of an eighty-year-old음 person in an intensive care unit. Let us assume that heor she is being maintained on an external mechanical respirator. This eighty-year-old may be terminally ill, ֶீ may not be able to survive without the respirator. But if that human being has a functioning brain, there is noळ doubt on the physician's part that he is dealing with aliving patient. What is to be done for or to that patiegt $\mathbb{C}_{\infty}^{\circ}$ is a wholly different set of decisions which may Re $^{\mathrm{C}}$ made upon the basis of many other considerations, b no one would doubt that that human being is alize despite the fact that many bodily functions were beingo maintained mechanically.

Consider similarly a fetus. It is inside the most advanced intensive care unit ever designed - theo uterus. And it is being maintained by the most complex extracorporeal respirator known - the placenta. If this fetus has reached the age of eight weeks, a wealth of evidence indicates that its brain has begun functioning electrically $(7,8,9)$. This fetus may be terminally ill, or: it may continue to grow through its next eighteen years of life and to develop for the next eighty. It cannotio survive without external ventilatory support. These things are a function of probabilities. What is a matter of fact is that medically if a fetus is analysed in the same way as a born human, then at eight-weeks gestation with a functioning brain present, it is a living human being in the biological sense of that term.

In fact I would argue that when the fetus has an functioning brain, one cannot advance any logicaf argument to show that that fetus is not a living human being, at least from the point of view of medicine. Questions about the probabilities of that fetal human' $€$ future existence have no more place in thate fundamental determination than they do in the case of the eighty-year-old $(10,11)$. But they may be taken into5 account along with many other criteria in deciding how that human will be treated.

My view is that fundamentally, the positions of the eighty-year-old born human and the eight-week-old fetal human are analogous. I attach no ethical magic to 
the process of birth. But, for example, I know of no logical formulation which requires that if a human being is alive, it must $a$ priori and under all circumstances be allowed to continue to live.

Before continuing, let me make clear to the reader what I mean by a 'functioning brain'. The brain can be divided into cortical and subcortical sections. The former controls most associative (ie thinking) structures. The latter 'primitive brain' influences behaviour and emotion, but primarily is concerned with regulating body functions. In determining 'brain death', the British argue (inter alia) that absence of reflexes from the subcortical (brain stem) area indicates death of the brain (and hence eventually of the body (12)), while in the United States, there is a requirement for cessation of brain waves measured by electroencephalograph (EEG) $(10,11,13)$. Either approach encounters difficulty in dealing with cases where cortical function is lost but primitive areas of the brain remain alive to control breathing - a 'severe vegetative state' - a medico-ethical limbo wherein a human is technically still alive or rather 'not quite dead' but is no longer capable of higher brain functions.

In the fetus, the situation is naturally reversed. The primitive, sub-cortical brain comes into being at five weeks as an organised unit (even more primitive neuronal cells exist before that at three - four weeks gestation but are not organised in a manner recognisable as a brain). Cerebral hemispheres differentiate at seven weeks (14) and as previously noted, EEG activity has been demonstrated at eight weeks.

I have chosen to use the eight-week point for this paper since there is no doubt at that point that an active brain by electrical and anatomic definition is clearly present. Whether the brain is actually sufficiently organised to produce brain-waves or reflexes during the fifth to the seventh weeks of life is speculative and a matter for further research. So too is the question of whether the presence of lower brain structures without a cerebral cortex is truly representative of a living human - a matter of considerable debate and uncertainty.

What is important in this discussion is my contention of the central nature of the brain in defining a human being throughout life, and not the specific point at which we define the presence of the operating brain. For the time being I will continue to use eight weeks gestation as the current best point for such a definition, but subject to refinement in coming years. My personal feeling would be to stick with the development of the cerebral cortex at seven to eight weeks as the deciding point in becoming a human being because just as, in assessing death, we are concerned with the 'death of the brain as a whole' and not the death of the 'whole brain' (ie of every single cell) (15), so we should prefer the 'integration of the brain as a whole' as the starting point for human beings.
Advances which allow for direct, non-invasive measurement of fetal EEG or can differentiate cortical from subcortical brain activity may some day refine this point by one week or less, but the principles would remain the same.

Parenthetically, I should note that whether or not the fetal brain 'thinks' or 'feels' at this early point in development is also speculative, and certainly not relevant to one's definition of a human being. We would not ask such a question about the eighty-yearold on assisted ventilation in determining life versus death, though such considerations might play a role in deciding whether or not to continue ventilatory support.

\section{Implications of the theory}

\section{1) A SYMMETRICAL VIEW OF HUMANNESS}

The brain-life theory simply stated is: "Whenever a functioning human brain is present, a human being is alive.'

Whether that being is in utero or ex-utero, whether that person will die in the next minute, or at age nine weeks or ninety years is immaterial to this definition.

If we apply this theory consistently, we can achieve a view of humanness which is unmatched in its logic and symmetry. Before the brain begins to function, what we have is a set of tissues or a series of organ systems. They may be functional, but without the presence of a human brain they are unco-ordinated and without the ability to develop personality. On the other side of the curve of life, when the brain ceases its activity, what remains are unco-ordinated organ systems which may be functional. They will eventually degenerate to the tissue level and then to the level of isolated living human cells until the last cell ceases to function (Figure I).

From first cell division to last cell death, we can see a spectrum of human existence (Figure I). For me, the fringes of that spectrum represent what Dr Kushner calls 'having life' while the centre with a functional brain represents 'being alive' as a full human (5). However, unlike Dr Kushner, I would argue that this definition of humanness is and should properly be solely a matter for science and medicine to determine. How we then decide to treat living humans - whether we operate or experiment upon them or whether we remove extracorporeal life-support - these are the realms of ethics, law and public policy. The scientific definition of humanness has relevance for these disciplines, but may not necessarily be the sole criterion for decision-making. Before examining some of these implications of the brain-life theory, let us briefly consider the problematic implications of asymetrical theories of humanness which are now being used.

The 'at conception theory' says that a human being exists at the moment when haploid human gametes fuse into a fertilised diploid human egg. Essentially 
Figure 1

THE CONTINUUM OF HUMAN EXISTENCE

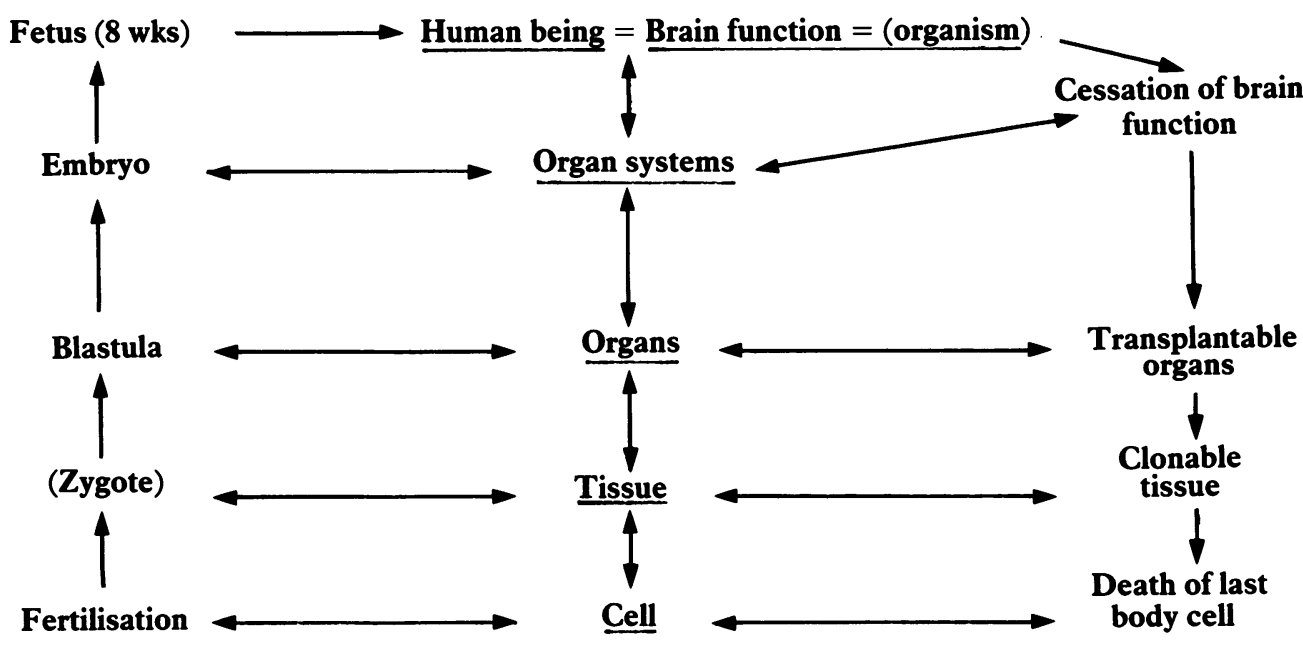

this theory says that a single cell is in fact a human being. That this is difficult to accept scientifically becomes clear when one considers developments which will all too soon be confronting us.

Sometime in the not very distant future, probably in our quest to understand cancer, we will discover the mechanisms for unlocking the genetic code which prevents unchecked cell division. Since every single human cell contains the full genetic information of every other cell, it will become possible to take a skin cell and cause it to divide and differentiate into any desired organ, or even into a complete human being, genetically identical to the donor. The process is called 'cloning'. Will we then say that every skin cell is a human being? Rather should we not say that both zygotes and skin cells represent potential human beings with differing probabilities of actually becoming a full human?

I should make it clear that valuing the point of conception is a perfectly reasonable ethical position, but it should be realised that what one is putting a premium on is a potential and probability for humanness, and that it is not necessarily true, nor important, to argue that a fertilised egg is in fact a full human being at conception.

The other major theory, 'viability', says that a fetus should be considered to have achieved full humanness when it can survive outside the mother. This theory has three problems. First it is fundamentally flawed because it treats in utero humans differently from $e \frac{\mathrm{D}}{D}$ utero humans when we know very well that nothing physiologically important happens at the exact instan of birth except that the fetus is exposed to the cold ais of the world. Some moments thereafter with cessation of placental function, that fetus must function with its़. own internal respiratory apparatus, or receive externat mechanical ventilatory support. When one accepts thẹ viability definition of a human being, the paradox of the famous Edlin case (16) may result.

Dr Edlin, using one set of criteria, namely viabilityô performed an abortion but moments later the delivered conceptus purportedly evidenced a 'vital sign' 웅 respiratory effort. Now that the fetus was 'born' it wass alleged that Dr Edlin should have suddenly switche⿻. over to a 'vital signs' definition of humanness, and should have resuscitated the baby, presumably untiा? heart function could not be established or until no brain function could be demonstrated. The court held that Dr Edlin could reasonably be held to only one definition - the viability criterion originally usedo However, the inconsistency of 'switching definitionst at birth remains a problem which will not go away and poses a situation which remains illogical from श्र scientific perspective.

Second, the viability definition is artificial because $\mathbb{\mathbb { R }}$ is dependent on the state of the machines which we use to enhance survivability at birth. Looking again into the not distant future, we will become more and more 
capable of 'salvaging' fetuses of earlier and earlier gestation. Primitive extracorporeal membrane oxygenators have already been in use for a decade and our tissue culture abilities are growing by leaps and bounds. The artificial womb and the artificial placenta are within sight. Once we develop them, we may suffer a logical reductio ad adsurdum when a fertilised ovum or a cloned skin cell - become 'viable'!

Third, we must ask what 'surviving' means. Even if we leave out sticky questions of 'quality of survival', do we mean a one per cent chance of survival or even less, or a five per cent or ten per cent chance? Depending upon which we choose, the point of humanness could vary right now from 22 weeks gestation to 28 weeks, subject of course to change with notice being given in a prestigious medical journal.

Questions of probability of survival do not make sense in the basic biological definition of what constitutes a human being. Let us take one more look into the future for the case of another eighty-year-old on the mechanical ventilator. Let us presume that his or her brain has been destroyed, but other body organs remain functional. What if - and some day it may be possible - we could transplant a brain into that eightyyear-old body?

The viability definition is of little value in this case. But the brain-life definition tells us that we are not transplanting the brain - we are transplanting the body! And if we place a functioning brain inside a robot and produce a cyborg, that must also be considered a living human being.

The brain-life definition of human life is a consistent, verifiable, and very basic theory which will be valuable beyond the current decade and the current technology. Part of its attractiveness rests in the symmetrical view of the beginning and end of human existence which it offers. It is also based on relatively objective rather than heavily evaluative criteria.

Concluding with regard to viability, one can also see that while it may be ethically reasonable to consider questions about viability when deciding when to treat or when to terminate life-support, these issues and this concept should not be confused with the biological definition of a human being.

\section{2) IMPLICATIONS FOR ABORTION}

The basic fact which the brain-life theory forces us to recognise is that an abortion before eight weeks gestation kills potential human life and that thereafter an actual human life is terminated. Three alternatives for law and policy become logical when the theory is accepted.

i) One can choose the Catholic position - properly stated - that even potential life should be preserved, recognising the paradoxes and difficulties which we have already discussed plus those which will be added in further discussion.

ii) One can opt essentially to follow the reasoning of the
Supreme Court in Row $v$ Wade (17). What the court saw was a question of rights in conflict. It stated that State interest in the fetus as having coequal rights begins only when the fetus has a reasonable chance of survival. This is a rational use of the concept of viability, not as a definition of humanness, but as a point when the State should extend equal protection. Clearly, the fact that late abortions kill a human being from my point of view does not $a$ priori mean that the State must not allow such killing. Proponents must, however, recognise that late abortions end an actual human life and not just a mass of tissue with human potential. Furthermore they must be aware of the fact that viability is likely to continue to occur earlier and earlier in gestation as medicine advances.

iii) One could allow abortion 'on demand' up till the eighth week post-conception, but then require substantial reasons for later abortions which by the brain-life definition would cause a human being to die. For example, it might be acceptable to discontinue the placental 'assisted ventilation' for the same reasons that one could discontinue mechanical ventilatory assistance in ex utero humans, ie terminal illness (severe genetic anomaly), extremely poor prognosis for survival or quality of survival (high thoracic meningomye'ocele) or brain damage not amounting to brain death (anencephaly (18)).

If the clinician is honest with himself, this last alternative is not really satisfactory. Among the cases that really bother us is the case of the thirteen-year-old girl who is pregnant after being raped by her father. Given a supportive family, both the girl and the baby might do well, but in such a case the family is always irreparably flawed. Adoption after birth forces the unprepared, stigmatised and already traumatised teenager to go through the additional stress of nine months of pregnancy. Then, given the survival instincts built into women by millions of years of evolution, many adolescent women will 'bond' with their child and eventually refuse to give it up. To overcome this instinctual love and the fantasies which come with it requires a very mature thinking process. Many young teenagers simply have not yet developed that level of ability. The result from the point of view of clinical medicine is a disaster for mother, child, relatives and society in general. From a practical, clinical perspective, an abortion may often be by far the most satisfactory among unpleasant alternatives. Honest physicians recognise this as a core dilemma.

In addition, the fact that young women tend to deny early pregnancy signs, even though pregnancy can now be diagnosed by simple urine tests with great accuracy as soon as a menstrual period is missed, makes the third alternative seem unworkable. However, as so often happens, scientia ex machina is about to add a new wrinkle.

Within the next decade, a new class of very safe drugs will appear which function by blocking the action of the hormone progesterone at the cellular receptor sight. Interrupting the action of progesterone 
will cause termination of any pregnancy without a wellestablished placenta and perhaps beyond. Thus we will find ourselves faced with the first completely safe and universally effective 'morning after pill' and a simple, effective abortifacient which may replace suction as a method of choice for aborting very early pregnancies, ie those less than eight weeks gestation!

I predict that this will become a very popular, publicly available back-up or even primary method of birth control. The brain-life theory has no ethical problem with the use of this early abortifacient and its advent may make the third policy alternative based on brain life the best alternative for developing societal consensus on this difficult issue. Very early abortions will become the norm and late abortions will be limited in numbers and for specific socially acceptable reasons.

\section{3) IMPLICATIONS FOR IN VITRO FERTILISATION}

The use of the brain-life theory with respect to in vitro fertilisation is essentially related in the recent article by Singer and Wells (6). It would be acceptable by this theory to grow in culture all forms of human tissue up to the point when brain function begins. If we develop artificial placenta function to the point of growing eight week fetuses, then we will have to face the question of what to do with these humans and whether their life could be terminated. Meanwhile current techniques are nowhere near allowing humans to be grown out of the womb. What is grown is by my account tissue only, albeit with greater current potential for humanness than say HeLa cells. Such tissue can be treated and disposed of in the same way as any other human cultured tissue, unless we choose to value that potential differently.

\section{4) IMPLICATIONS FOR FETAL RESEARCH}

The brain-life theory also offers a clear choice-point for contending with the ethics of fetal research. Prior to brain function, experimentation on cultured, aborted, or definitely-about-to-be-aborted embryonic tissue need not be subject to any special rules unless again we value potential as much as actuality.

After eight weeks there is a question of who could consent to research on the young human. In keeping with current practice, I would allow parents to consent for the child to in utero research which had passed muster by ethical review boards. If the fetus is aborted, but non-viable, then I would require a brain-death criterion to be met prior to experimentation, just as we would require in the case of any other human in transplantation or cadaveric research. This might limit some forms of research, but would be the only consistent approach. I will not go further since the full discussion of this concept would require a paper of its own. Suffice to say that brain-life criteria may play an important part in making ethical decisions as the possibilities for fetal research expand over the next two decades.

\section{5) IMPLICATIONS FOR TREATMENT OF RAPE VICTIMS}

Female victims of rape may be at risk for pregnancy and therefore physicians offer them the use of a high $\frac{}{-}$ dose oestrogen regimen (two high-dose oraf contraceptive pills taken twice, twelve hours apart) to prevent a most unwanted conception. This 'morning after' treatment is highly effective, but must be givens? within 72 hours of the rape (19). Some suclo treatments, now rarely used, such aș diethylstilboesterol injections, may be teratogenic ops. carcinogenic). The Catholic Church officially espouse $\$$ the position that this treatment represents an abortion (20). Thus, even though this is an emergency treatment, many Catholic hospitals forbid physician? from prescribing post-rape oestrogen anti-pregnancy $\vec{\omega}$ prophylaxis (21).

Some Catholic theologians have argued on the basi⿸户㔾 of theories of probabilities that post-coital contraception is not really an abortion (22). That is $\vec{A}$ there is only a 'chance' of unknown proportion that $\dot{a}$ conceptus is killed. The brain-life theory simply state® that such treatment kills no human life, though if prevents a probability of its occurrence. At most, a single human cell is prevented from implanting in the uterine lining. Thus in at least this instance, som 8 Catholic theologians can already find some correspondence between their own views and thळ brain-life definition.

\section{6) IMPLICATIONS FOR DISPOSAL OF FETAL REMAINS}

'Right-to-life' groups have sued in court in Califo in order to be able to give aborted fetuses a religious 요 burial. The brain-life theory says that society should not require such funerals until the fetal deat encompasses a human ending - ie after the conception has reached eight weeks gestation.

Interestingly, those who argue for an 'at conception definition of human being have not carried thei argument in this area to its logical conclusion. If fertilised ovum is a human being, and since significan numbers of human pregnancies never implant or abor: rapidly because of genetic flaws, then it follow that many 'normal' female menses carry the 'body' of dead human being! If one follows logic consistently즐 then women should bury their menstrual flow with due religious ceremony on the chance that a spontaneous abortion has occurred.

This is not advocated by any civilised society an harkens back to ancient superstitious behaviour in primitive society. Yet it would be the logical extension of the theory that a single fertilised cell is indeed human being.

\section{Conclusion}

By accepting a functioning brain as a medicaf definition for humanness, one can achieve a verwo reasonable, scientifically grounded and consistent view of human life. Such a definition allows us to look at alo of life from the development of a single cell to the deat 18 of the last cell in a body in the same way. We need not encounter any logical dilemmas if we apply a brain-life 
test and we can use it as an instrument to aid policy and ethical decisions. However, though this theory can improve and clarify the logic of those decisions, ultimately our social answers to ethical questions lie not in facts but in what value we put on those facts including a human life or its potential. No biological theory of humanness defines such values nor ever will. But a soundly based scientific definition of a human being can clarify decisions to the point where areas of potential societal compromise can become clearer.

Science can, in a relatively value-free manner, suggest a solid definition of when in the continuum of life a full human being exists. Will science consider the possibilities and take up President Reagan's challenge?

\section{Dedication}

The original work on the concepts presented in this paper was performed in the summer of 1975 at the Kennedy Institute for Bioethics at the Georgetown University Medical Center, while the author was still an undergraduate college student. This paper is dedicated to the memory of the late Andre Hellegers, $M D$, who at that time was the director of the Bioethics Institute. Dr Hellegers was one of the true giants of medicine in this century; clinician, scientist, philosopher, teacher, and above all, an incredibly educated human being. His steadfast dedication to openness in scientific and ethical pursuits allowed him to encourage the thinking of a heretical young student, even though the implications of the author's theory might prove unsettling to Dr Hellegers's strongly held ethical beliefs. Without Dr Hellegers this paper would never have been published. I miss his wise counsel, and so do all those concerned with medical ethics.

Fohn M Goldenring MD MPH is a physician and Assistant Professor of Pediatrics, Adolescent and Preventive Medicine in the Department of Pediatrics, New York Medical College, Valhalla, New York 10595.

\section{References}

(1) Holden C. Senate commences hearings on human life. Science 1981 ; 212: 648-649.

(2) Goldenring J M. Death, life and abortion: the implications of the fetal EEG. Unpublished thesis. Kennedy Bioethics Center, Georgetown University 1972.

(3) Hellegers A. The beginnings of personhood: medical considerations. Perking journal 1973; 3: 11-15.
(4) Goldenring J M. Development of the fetal brain. New England journal of medicine 1982; 307: 564.

(5) Kushner T. Having a life versus being alive. Fournal of medical ethics $1984 ; 10$ : 5-8.

(6) Singer $P$, Wells $D$. In vitro fertilisation: the major issues. Fournal of medical ethics 1983; 9: 192-195.

(7) Hellegers A. Fetal development. In: Beauchamp T, Walters L, eds. contemporary issues in bioethics. California Dickenson Publishing, 1978: 194-199.

(8) Bergstrom R M. Development of EEG and unit electrical activity of the brain during ontogeny". In: Jilek L J, Stanislav T, eds. Ontogenesis of the brain. Czechoslovakia: University of Karlova Press, 1968: 6171.

(9) Ellingson $\mathrm{R} J$, Guenter $\mathrm{H}$ R. Ontogenesis of the Electroencephalogram. In: Himwick W A, ed. Developmental neurology. Springfield, Il: C C Thomas Books, 1970: 441-474.

(10) Report of the ad hoc committee of Harvard Medical School. A definition of irreversible coma. Fournal of the American Medical Association 1968; 205: 337-340.

(11) Report of the medical consultants on the diagnosis of death to the President's Commission for the Study of Ethical Problems in Medicine and Biomedical and Behavioral Research Guidelines for determining death. Fournal of American Medical Association 1981 ; 246: 2184 2186.

(12) Pallis C. ABC of brain stem death: from brain death to brain stem death. British medical journal 1982; 285: 1487-1490.

(13) Pallis C. ABC of brain stem death: the position in the USA and elsewhere. British medical journal 1983; 286: 209-210.

(14) Moore K L. The nervous system. In: Moore K L, ed The developing human: clinically oriented embryology. W B Saunders and Co: Philadelphia, Pa: 1982: 375-412.

(15) Pallis C. ABC of brain stem death: reappraising death. British medical journal 1982; 285: 1409-1412.

(16) Ramsey P. Viability and Edlin: Ethics at the edge of life: medical and legal intersections. New Haven, CT: Yale Press, 1978: 94-142.

(17) Bachman Justice Henry. Roe v Wade: US Supreme Court 1973: 70-18.

(18) Chervenak F A, Farley M A, Walters L, et al. When is termination of pregnancy during the third trimester morally justifiable? New England journal of medicine 1984; 310: 501-511.

(19) Hatcher R A, Stewart C K, Stewart F, et al. Contraceptive technology. New York: Irvington Publishing, 1982-1983: 152-154.

(20) Moraczewski A S, ed. Ethics and medics; vol 5. St Louis: Pope John Center, 1980: 2-3.

(21) Goldenring J M. Denial of antipregnancy prophylaxis to rape victims. New England medical journal 1985; 3n: 1637.

(22) Tauer C A. The tradition of probabalism and the moral stature of the early embryo. Theological studies $1984 ; 45$ : 3-33. 